\title{
Singing behavior via reduced predation risk
}

\author{
David M. Schruth, Ph.D. ${ }^{1}$ \\ Joseph Jordania, Ph.D. ${ }^{2}$ \\ 1. University of Washington \\ 2. University of Melbourne
}

\begin{abstract}
A surprisingly diverse array of animals produce sounds with song-like qualities in order to communicate who and where they are to conspecifics when their senses of smell, and in some cases vision, are rendered ineffectual across long or occluded distances. Social factors are typically considered to drive the evolution of such calls, but here we consider broader effects of habitat which are often difficult to observe, measure, and analyze, and are thus typically neglected. We tested the hypothesis that ecological protections from predation enabled animals to call by neutralizing the risk inherent in vocally forfeiting position. We compiled data on human and nonhuman singing species that live in arboreal, aerial, or aquatic (i.e. non-planar) habitats, to measure the degree to which each presumably helps to reduce predation and thereby allow singing. We find that singing species may forfend predation via larger size as well as increased levels of arboreality and flight. Arboreal primates and birds do appear to sing significantly more so than terrestrial ones. Hunting and warfare in humans, respectively, likewise correlate with the musical features of rhythmic and melodic tension. In all species explored, however, only body size universally correlates positively with singing behavior. We conclude that effects of predation, especially when viewed in a larger, food-web context, seem to play a central role in determining who sings and who does not.
\end{abstract}

License: Attribution-NoDerivatives 4.0 International (CC BY-ND 4.0)

This work, its predecessors, and any ideas therein may be shared freely, assuming that academic attribution standards, via citation, are honored.

DOI: $\underline{10.31234 / \mathrm{osf} .10 / \mathrm{u} 9 \mathrm{~m} 8 \mathrm{z}}$

First-Published: 2020/12/29

Last-Modified: 2021/02/28 


\section{Introduction}

An impressive number of animals exhibit song-like and musical behavior (Hauser and McDermott, 2003) including species ranging from the 100 ton singing blue whale to the $100 \mathrm{~g}$ duetting tarsier. Despite this variety of shapes, sizes, and methods of conveyance, all singing animals appear to use these complex calls to relay location and unique identity to conspecifics across aerial or aqueous habitats, which are often chemically or visually impeded by distance, turbulence, wind, or foliage (Slater, 2000). Any such blatant appeals to allies and conspecifics, however obfuscated by this media, are still quite dangerous as they also entail a cost in the forfeiture of clues to such whereabouts to predators. Researchers have typically focused on social factors driving the evolution of singing behavior (Geissmann, 1984; Catchpole, 1987; Schatral, 1990; Miller, 2000), but many new approaches have begun to look at the influences of habitat (Morton, 1975; Mitani and Stuht, 1998; Boncoraglio and Saino, 2007), which are often difficult to observe and measure.

We propose, that despite tremendous size differences among vertebrates, all singing species share the common attribute of occupying a position in the food chain where they can safely vocalize without negative predation consequences. That is, singing species ought to be trophically dominant such that they are rarely prey to predators or victims of aggression by sympatric competitors. These various forms of trophic security manifest in whales, birds, primates, and humans in that they are gargantuan, can fly, use trees, or use tools (respectively) to secure position atop each of their food webs and hence minimize predation. The observation that singing species are represented by thousands of aerial and arboreal species, by scores of aquatic mammals, and yet are nearly entirely absent (except humans) among habitually terrestrial species, has been surprisingly neglected thus far. Primates, for example, have an especially encumbering relationship with predation security in the trees-evolutionary successful due to mass that is optimally distributed over anatomy specialized for embracing rather than clawing into arboreal substrate. Thus, an arboreal ecosystem allows for the distribution of species at various heights on tree branches according to their weight (Jordania, 2014, pp. 17-21) and more efficiently so for primates than their non-primate predators along more distal positions. But even the heaviest extant lemur, Indri, the most sonorous mammal in Madagascar, is rather well protected from predation risks as venomous snakes and large cats are not native to the sub-continent. Further acoustic evidence for the vulnerability arboreal species may experience when terrestrial is evidenced by their tendency to become silent when they visit the ground for short periods (Catchpole and Slater, 1995, pp. 74-76).

Gibbons comprise the only living, deep-clade example among extant apes and thereby they provide a unique glimpse into how our ancestors may have behaved during the Miocene gap-a fossil-absent period of time between our divergence with monkeys, at 15 mya, and the hominin 
fossil-rich Pliocene, 5 mya (Reichard, Hirai and Bareli, 2016). While it is unlikely that our mutual hominoid ancestors exhibited the high degrees of daily singing that gibbons do today, there are undeniable similarities between the female gibbon great call, the loud call of orangutans, and the chimpanzee pant-hoot progression (Geissmann, 1993). Likewise, it is equally unlikely that the ancestor of all apes was an obligate brachiator, although many anatomical specializations for brachiation persist in all modern great ape lineages. Thus the common ancestor of all apes likely did sing and probably brachiated, just to a lesser degree than modern gibbons. One of us is a proponent of the hypothesis that such active arboreal locomotion co-evolved broadly with singing behavior (Schruth, 2006; Schruth and Templeton, 2014). This agile form of extreme terminal-branch enabling movement may have been even more protective against predators, than the more ancestral, leapingbased program, and could have been a primary emboldening factor allowing for such highly salient territorial calls. This connection between overhead arm-swinging and singing may have carried over into similar terrestrially territorial signals of temporal (Calvin, 1983) and spatial abilities for ballistics (Schruth, 2005) —a behavior that was perhaps also useful during the multi-million year transition to life on the ground.

The defense systems of early hominins is another generally neglected sphere in evolutionary scholarship (Hagen and Bryant, 2003). Human evolution towards terrestriality, for example, is complicated by the fact that early hominins were not the largest African mammals, but further, we evolved in a habitat that could be considered among the most severe (Tappen, 1995) and carnivorehazard prone ecosystems worldwide. Human music, likewise, is also a complex puzzle, in that it contains exceptionally sophisticated rhythmic patterning (Bispham, 2006) when compared to other forms of animal musicality. One of us has suggested that hominins used the power of the united sound of singing, stomping, hand-clapping, and rock-hitting as acoustic defenses from predation (Jordania, 2008). This form of acoustic defense is evidenced by the observation that singers can enter, via rigorous rhythmic group dance, an altered state of consciousness, or "battle trance,” where participating group members do not feel fear or pain, and are dedicated to the group interests with extreme neglect for self-survival. Although still mostly neglected in scholarly research, the phenomenon of the battle trance has been widely used in practice by the military combatant groups for millennia, in traditional societies (Jordania, 2011), and centuries, in contemporary military forces (Ehrenreich, 2011).

Here we utilize various datasets from both human and animal sources to test our hypothesized predationally protective precondition for singing behavior. Datasets including potentially protective variables of size, habitat, and behavior were downloaded and compared against singing behavior in each clade. We find that in general our observation holds true with size across all animals, but is more mixed with regard to habitat or technology in birds and humans. 


\section{Methods}

Attempts to deduce a broad evolutionary origin of song across so many taxa is rendered difficult due to the lack of a rigorous analysis-conducive definition (Schruth, Templeton and Holman, 2019a). But because these four taxa (whales, birds, primates, and humans) all unambiguously contain singers, we merely relied upon reported observations of "songs," which we understand here to essentially be saliently distinctive and elaborately patterned long calls. We also collected size and relevant habitat variables from each of these four main singing taxa. For aves, we used the All About Birds ${ }^{1}$ on-line catalog of north-American species in order to obtain various measures of body size and general habitat variables as well as a count of the number of different call types cataloged with "song” in the title. For cetaceans, we gleaned its wikipedia ${ }^{2}$ page to obtain size data and mentions of the word "song” in the text. These initial mentions were then subsequently investigated to determine if there were typically one or multiple songs. For primates, we used general locomotion categories (Jurmain and Nelson, 1994) and vocalization categories (Wich and Nunn, 2002) in a cross-tabulation to assess the effects of habitat utilization on song production. Additionally, within primates, we also tabulated a measure of song syllable reappearance diversity (Schruth, Templeton and Holman, 2019b) for within-family comparison of musicality alongside body mass. For humans we downloaded data from the Natural History of Song [NHS] database (Mehr, 2018; Mehr et al., 2020), the Standard Cross Cultural Sample (Murdock and White, 1969) database, and the Binford hunter-gatherer [BHG] database (Binford, 1962), in order to compare song variables with potentially predation protective indicator behaviors such as hunting and warfare.

\section{Results}

Size had the clearest positive association with singing behavior in that larger animalswhales ( $p<0.001$ ), singing birds (wingspan; tree; $p<0.4$ ), primates (callitrichidae; $\mathrm{p}<0.35$ ), and hunter-gatherer humans (height; $p<0.4$ ) —all seem to sing more musical songs (Table 1, Fig 1). While individually many of these probabilities may not be statistically significant, when combined, a joint probability of all positive associations, is exceedingly unlikely merely by chance. We determined that there are five outstanding species of cetaceans that unambiguously exhibit singing behavior including the Beluga, Fin, Bowhead, Humpback, and Blue whales_-four of which are in the top five percent of largest size overall (Tables 1 and 2). Habitat effects also played an important role in determining singing behavior with arboreal birds (Fig 1; Table 3) and primates (Table 4). In

1 http://allaboutbirds.org/ accessed in 2014 (data tables used have been uploaded to https://osf.io/t5rdk/)

2 http://en.wikipedia.org/wiki/Cetacean (scraped HTLM pages and tables have been saved on https://osf.io/t5rdk/) 
addition to forest dwelling verities, woodland and grassland species also had a striking number of songs (Table 3). Singing species were orders of magnitude more prevalent in forested and wooded areas than compared with those that were not, in agreement with the complimentary discovery that duet-singing evolved in non-migratory birds (Logue and Hall, 2014). For primates, the largest arboreal species on each respective island sub-continents were also singers: Indri entirely on Madagascar, gibbons largely on Java and Sumatra, and tarsiers across various small islands of the Malay archipelago (Table 5). The heaviest primates in each subfamily also had the most complex songs as measured by ARDI. Humans also showed higher levels of melodic tension with increased warfare $(p<0.02)$ and rhythmic tension with hunting $(p<0.002)$ although no other combinations or variable types were significant. For example, warfare weapons was positive (not significant) and defensive weapons was negatively correlated (Fig 2).

Figure 1. Bird wing-span increases as a function of song count for singing species
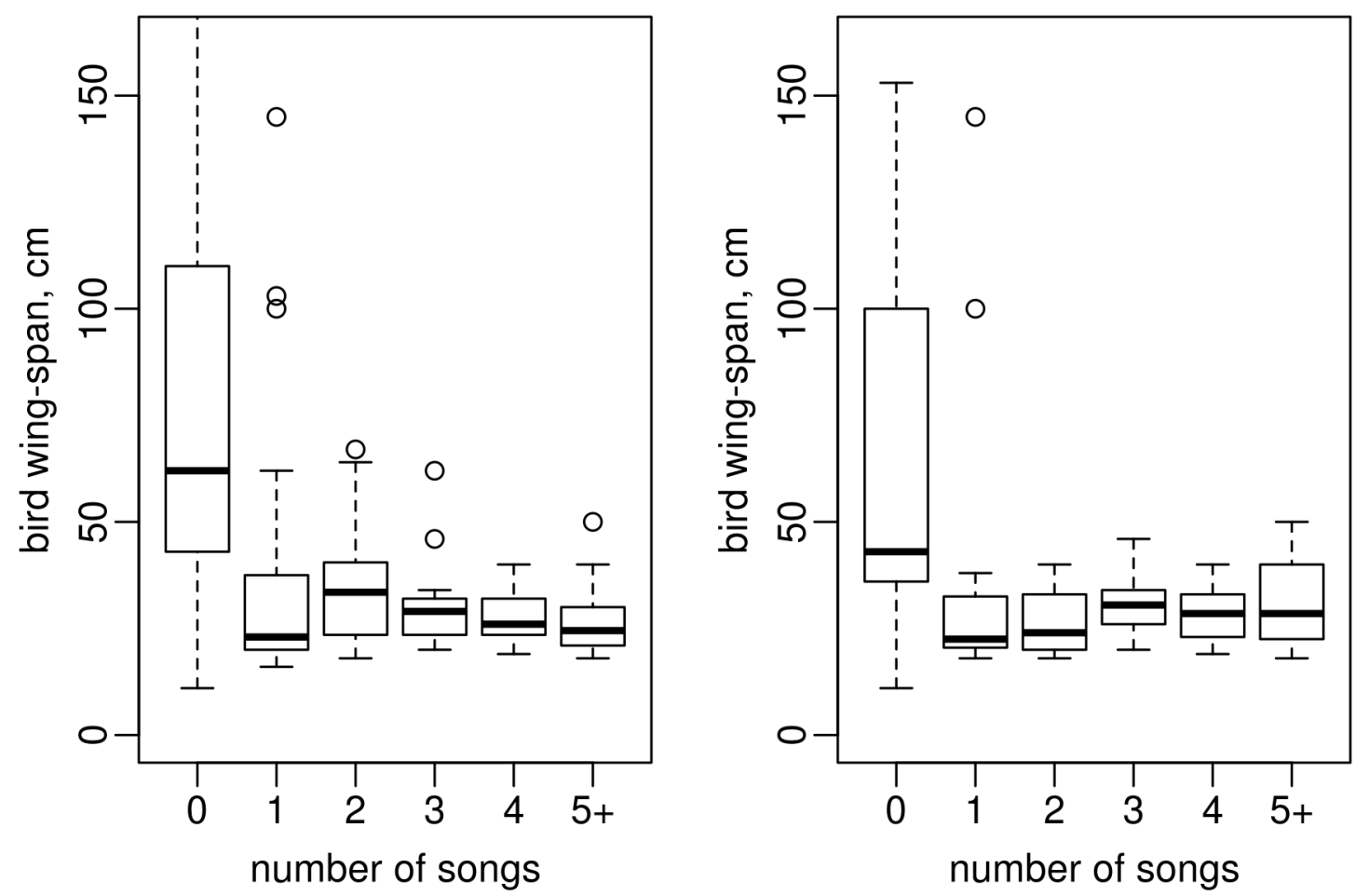

All species (left; $n=446$ ) and a subset of species (right; $n=119)$ that nest in trees. While there is a clear increase in multiple-song singing birds (over single-song birds) as a function of wing-span in global dataset (left), a much clearer and nearly monotonic correspondence manifests when we just look at tree-nesting birds (right). 
Table 1. Whale mass versus song count

Whale species grouped into discrete mass categories (in tons) versus singing status.

song count

$\begin{array}{lrll}\text { mass } & 0 & 1 & \text { multiple } \\ (0,20] & 74 & 0 & 1 \\ (20,40] & 3 & 1 & 0 \\ (40,80] & 3 & 1 & 1 \\ (80,100] & 0 & 0 & 1\end{array}$

Table 2. Whale species who sing charted by body mass, geography, and song data.

Singing species are not only larger but also tend to feed near icier polar regions

\begin{tabular}{|c|c|c|c|c|c|c|c|c|}
\hline & species & breed & feed & & mass, tons & count & $\operatorname{sex}$ & description \\
\hline Beluga & Delphinapterus leucas & estuaries & all & Arctic ice & 1.5 & several & both & bird-like calls \\
\hline Aun & Megaptera novaeangliae & tropical & polar & Antarctic ice & $25-30$ & 1 & males & complex song \\
\hline Fin & Balaenoptera physalus & & global & Antarctic & $40-50$ & several & males & long, loud, low sounds \\
\hline Bowhead & Balaena mysticetus & Berring & Beaufort & North Atlantic & 60 & $100 \mathrm{~s}$ & males & long, complex \\
\hline Blue & Balaenoptera musculus & & global & & 100 & $<10$ & males & repeated co-occurring s \\
\hline
\end{tabular}

Table 3. Bird species counts by habitat and song count.

Per habitat percentages (right) were calculated by dividing counts (left) by row sums.

Presumably there is higher security from predation in more vegetated habitats (in yellow).

\begin{tabular}{|c|c|c|c|c|c|c|c|c|c|c|}
\hline \multirow{2}{*}{ habitat } & \multicolumn{2}{|c|}{$0 \%$} & \multicolumn{2}{|c|}{$1 \%$} & \multicolumn{2}{|c|}{$2 \%$} & \multicolumn{2}{|c|}{$3 \%$} & \multicolumn{2}{|l|}{$4+$} \\
\hline & & & & & & & & & & \\
\hline mountain & 7 & $78 \%$ & 2 & $22 \%$ & 0 & $0 \%$ & 0 & $0 \%$ & 0 & $0 \%$ \\
\hline forest & 33 & $29 \%$ & 51 & $45 \%$ & 7 & $6 \%$ & 12 & $11 \%$ & 11 & $10 \%$ \\
\hline woodland & 31 & $32 \%$ & 33 & $34 \%$ & 5 & $5 \%$ & 14 & $14 \%$ & 14 & $14 \%$ \\
\hline shrub & 14 & $33 \%$ & 13 & $31 \%$ & 1 & $2 \%$ & 5 & $12 \%$ & 9 & $21 \%$ \\
\hline grassland & 18 & $42 \%$ & 13 & $30 \%$ & 2 & $5 \%$ & 3 & $7 \%$ & 7 & $16 \%$ \\
\hline marsh & 20 & $59 \%$ & 8 & $24 \%$ & 3 & $9 \%$ & 0 & $0 \%$ & 3 & $9 \%$ \\
\hline lake & 18 & $90 \%$ & 1 & $5 \%$ & 1 & $5 \%$ & 0 & $0 \%$ & 0 & $0 \%$ \\
\hline river & 1 & $33 \%$ & 2 & $67 \%$ & 0 & $0 \%$ & 0 & $0 \%$ & 0 & $0 \%$ \\
\hline shore & 40 & $91 \%$ & 3 & $7 \%$ & 0 & $0 \%$ & 1 & $2 \%$ & 0 & $0 \%$ \\
\hline ocean & 21 & $95 \%$ & 1 & $5 \%$ & 0 & $0 \%$ & 0 & $0 \%$ & 0 & $0 \%$ \\
\hline desert & 4 & $57 \%$ & 1 & $14 \%$ & 0 & $0 \%$ & 2 & $29 \%$ & 0 & $0 \%$ \\
\hline town & 2 & $18 \%$ & 2 & $18 \%$ & 5 & $45 \%$ & 0 & $0 \%$ & 2 & $18 \%$ \\
\hline
\end{tabular}

Table 4. General locomotion categories vs vocalization types across primate species.

\begin{tabular}{|c|c|c|c|c|c|c|}
\hline \multirow[b]{2}{*}{ Locomotion Type } & \multicolumn{5}{|c|}{ Vocalization Type } & \multirow[b]{2}{*}{ Total } \\
\hline & none & loud call & long call & chorus & duet / song & \\
\hline vertical cling and leap & 2 & 10 & 14 & 1 & 6 & 33 \\
\hline true brachiation & 0 & 0 & 0 & 0 & 11 & 11 \\
\hline O.W. semibrachiation & 14 & 19 & 4 & 1 & 1 & 39 \\
\hline N.W. semibrachiation & 3 & 1 & 8 & 4 & 0 & 16 \\
\hline branch run and walk & 38 & 31 & 41 & 1 & 9 & 120 \\
\hline quadrumanous & 0 & 0 & 1 & 0 & 0 & 1 \\
\hline slow climb & 3 & 1 & 3 & 0 & 0 & 7 \\
\hline knuckle walk & 0 & 2 & 1 & 0 & 0 & 3 \\
\hline ground run and walk & 1 & 27 & 2 & 0 & 0 & 30 \\
\hline Tota & 61 & 91 & 74 & 7 & 27 & 260 \\
\hline
\end{tabular}


Table 5. Primate subfamiles who sing charted alongside size and geographic information.

\begin{tabular}{|c|c|c|c|c|c|c|c|c|c|}
\hline $\begin{array}{c}\text { Common Name } \\
\text { Titi monkey }\end{array}$ & Family & Subfamily & Genus & Species & Location & $\begin{array}{l}\text { Region } \\
\text { S. America }\end{array}$ & $\begin{array}{c}\text { Mass, } \mathrm{Kg} \\
0.99\end{array}$ & $\begin{array}{c}\text { Group size } \\
4.5\end{array}$ & $\begin{array}{c}\max (A R D I) \\
2.6\end{array}$ \\
\hline \multirow{6}{*}{$\begin{array}{c}\text { Marmosets } \\
\& \\
\text { Tamarins }\end{array}$} & Cebidae & Callitrichinae & Leontopithec & rosalia & S.E. Brazil & \multirow{6}{*}{ S. America } & 0.61 & 4.7 & 4.2 \\
\hline & Cebidae & Callitrichinae & Saguinus & mystax & Peru, W. Brazil & & 0.52 & NA & NA \\
\hline & Cebidae & Callitrichinae & Saguinus & labiatus & Bolivia, Brazil & & 0.51 & NA & NA \\
\hline & Cebidae & Callitrichinae & Callimico & goeldii & Peru, etc. & & 0.48 & 7.7 & 1.3 \\
\hline & Cebidae & Callitrichinae & Saguinus & fuscicollis & Brazil & & 0.35 & 5.0 & 2.6 \\
\hline & Cebidae & Callitrichinae & Cebuella & pygmaea & Brazil & & 0.12 & 5.7 & 1.9 \\
\hline \multirow{3}{*}{ Gibbons } & Hylobatidae & & Hylobates & syndactylus & Java, etc. & \multirow{3}{*}{ SE Asia } & 11.30 & 4.0 & 4.6 \\
\hline & Hylobatidae & & Hylobates & concolor & N. Vietnam, etc. & & 7.71 & NA & 3.6 \\
\hline & Hylobatidae & & Hylobates & leucogenys & S. China, etc. & & 7.37 & 3.8 & 3.9 \\
\hline \multirow{4}{*}{ Indri } & Indriidae & & Indri & indri & \multirow{4}{*}{ Madagascar } & \multirow{4}{*}{ SE Africa } & 6.34 & 4.3 & 3.7 \\
\hline & Indriidae & & Propithecus & diadema & & & 6.10 & NA & NA \\
\hline & Indriidae & & Propithecus & verreauxi & & & 3.50 & 5.1 & 0.9 \\
\hline & Indriidae & & Avahi & occidentalis & & & 0.90 & NA & NA \\
\hline \multirow{2}{*}{ Tarsiers } & Tarsiidae & & Tarsius & syrichta & \multirow{2}{*}{$\begin{array}{l}\text { Philippines } \\
\text { Sulawesi }\end{array}$} & \multirow{2}{*}{ SE Asia } & 0.13 & 1.0 & 2.3 \\
\hline & Tarsiidae & & Tarsius & spectrum & & & 0.12 & 2.5 & 6.0 \\
\hline
\end{tabular}

Table 6. Musical feature score averages compared between primate habitats.

$\begin{array}{rcccccc} & \text { syllables } & \text { repetition } & \text { transposition } & \text { rhythm } & \text { interval } & \text { tone } \\ \text { arboreal } & 3.16 & 0.61 & 0.16 & 0.59 & 0.51 & 0.57 \\ \text { terrestrial } & 2.67 & 0.68 & 0.12 & 0.62 & 0.43 & 0.57\end{array}$

Syllables are counted as unique spectral shapes whereas the other measures reflect probabilities of each feature occurring in a call. All scores were averaged across primate species $(n=58)$ after partitioning the table into each of the two habitats. Note that temporal features (repetition and rhythm) have slightly higher averages in terrestrial species whereas spectral aspects (transposition, and interval) have higher scores in arboreal species. Tone was surprisingly indistinguishable between the two habitats. Notice that call syllable diversity had the largest overall difference, favoring arboreal habitats. Understand also that rhythm, as used here, was originally defined to measure monotonically spaced units and therefore may underestimate the likely much more pronounced augmentation of rhythmic complexity in terrestrial, over arboreal, primate species. Raw data for these feature scores is available at https://osf.io/bvsfz 
Figure 3. Human music features plotted against hunting and warfare variables per society.

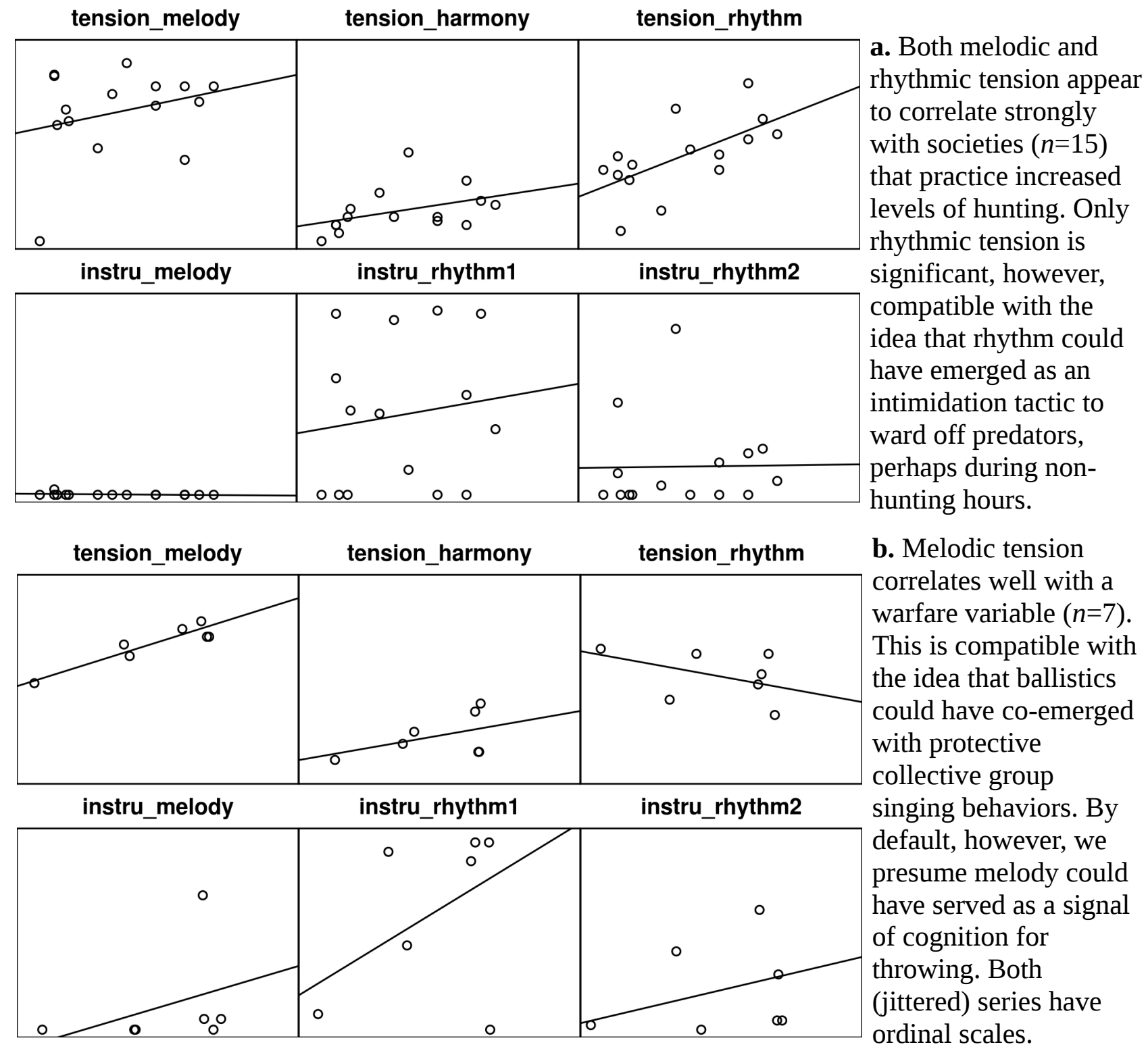




\section{Discussion}

Our main observations that protective effects of size and habitat enable animals to sing, is upheld after interrogating numerous independent data sources derived from both animal taxa and human societies. Some exceptions are obviously some ground-dwelling birds who may not need arboreal protection, perhaps if they inhabit islands where there are no natural predators. We were pleasantly surprised to detect such an island effect affirmed in primates as well. Within each singing primate family (and island) there does appear to be a general body mass and song complexity correlation. In whales, unfortunately, there are only very few data points to compare as the ocean could be considered to be only one large island, of sorts, with very few places to hide in order for sampling bottle-necks to select for the emergence of this relativistic trait. In humans, body mass surprisingly did not correlate well with singing, but height did. Furthermore, only certain features, such as melody and rhythm, correlated with warfare and hunting but not under all reasonable comparisons with many inter-related variables. The overall picture, however, is of statural security as prerequisite for comfortable singing behavior.

With regards to singing in relation to the timing of the emergence of human musicality, if we take into account that two singing primate species, humans and gibbons, diverged over 15 mya, and no other apes are singers, there seems to be two theoretical possibilities. First, humans and gibbons share the musical abilities from the common arboreal ancestor of the great apes that experienced an increase in terrestrial activity and presumably also moderate degrees of corresponding silencing in all but the human lineage. And second, the common arboreal ancestor of all apes was not a singer, and singing of gibbons and humans are not directly related, in which case humans must have developed singing after becoming terrestrial. In the light of the arguments and evidence presented in this article favoring (e.g. arboreal) protective effects that enable singing, we are most persuaded by the first scenario of continuity between ancestral, and likely more melodic, lesser-ape singing and, likely more rhythmically complex, hominin musicality (Fig 3, Table 6).

Singing, particularly coordinated group chorusing in humans, and perhaps in ancestral hominins, is considered, here and previously (Jordania, 2008), to plausibly be an effective defense to collectively fend off predators. In chimpanzees, evening “concerts” with loud calls, or evening singing and drumming in forest-dwelling pygmies (Kortlandt, 1973), employing loud noises, could have produced a Beau Geste effect (Krebs, 1977) when vocalizing in concert, perhaps using dissonant harmonies (Harrington, 1989), to ensure predators stay clear of the sizable and wellcoordinated group. It is important to note the evidence presented in our datasets here, however, indicates that individual stature, rather than group size, seems to most convincingly correlate with singing behavior. 
For early hominids, we reaffirm the suggestions that this gradual transition from trees to ground likely represented a monumental turning point in the evolutionary changes in both musical traditions and security strategies. Under such a transition, certain human-like acoustic display adaptations could have constituted important preconditions for survival in more exposed, semiarboreal settings. Indeed, this transition not only corresponds with the beginning of exponential growth in hominin brain sizes (Du et al., 2018), but is evidenced further by increasing use of tools (Susman, 1994). We maintain that ape-like brachiation may have pre-adapted hominins for ballistics thereby empowering this transition (Fig 3: blue arrows). Such audacious encounters with terrestrial threats could have been a key intimidation tactic, not unlike the Maori Haka war dance (Murray, 2000). It would not be surprising to discover further evidence- - beyond the handful of significantly aligned datum here - that ballistics, warfare, and other aggressive extra-group deterrents could also correspond with melodic display. We further speculate on other aspects of this inter-related transition to an increasingly carnivorous diet, such as the shift toward tool-use and drumming.

More specifically, we surmised that it is plausible that the primeval use of detached terminal-branches and stones involved multiple anti-predator functions, and not just as projectile weapons, but perhaps also as sound-generating tools, created by vigorously striking together (Jordania, 2008), akin to vigorous chest-beating or branch shaking displays of some apes (Hobaiter and Byrne, 2011) or low-frequency cues of body size by other mammals (Ravignani et al., 2017). This scenario is moderately evidenced by the significant correlation between rhythmic tension and hunting in modern hunter-gatherers (Fig. 2a). Such percussive deterrents could have also led to the occasional splitting of stones into sharp-edged tools useful for scavenging or butchering as well as enabling more aggressive encounters with predators (Jordania, 2014) or competitors (Fig 3: green arrows). In sum, proto-hominins seem to have possessed multiple survival-based pre-adaptations (e.g. brachiational terminal branch arm-swinging) that were likely co-opted for terrestrial security (e.g. projectile throwing) and into proto-musical practices (e.g. percussing of materials).

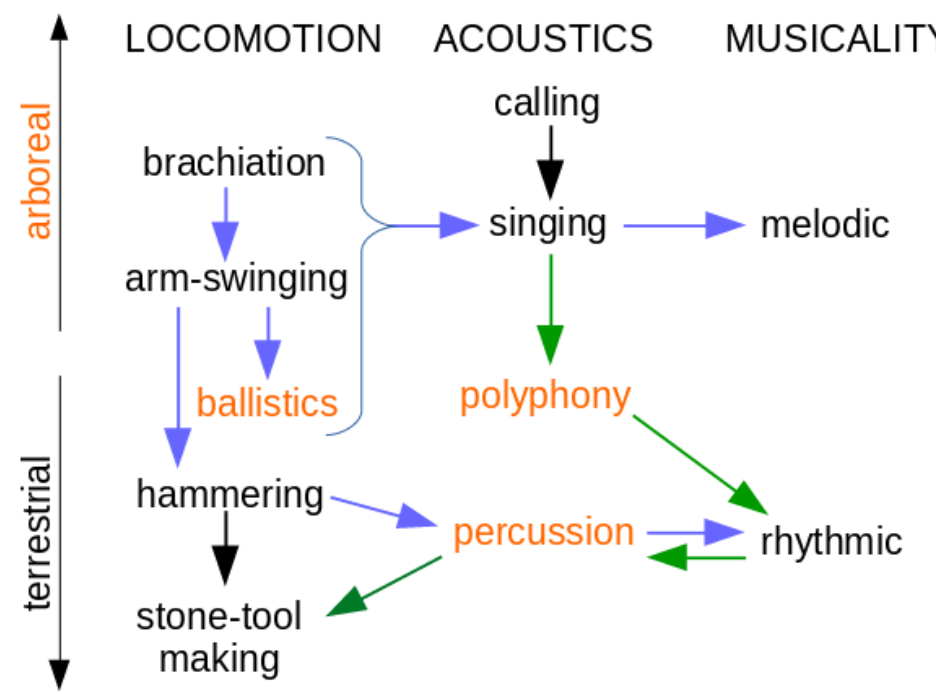

Figure 3. Possible progressions for the descent of hominins from trees and corresponding effects on musicality. Blue arrows outline avoidance-based locomotion cognition driving influences on the origin of melody and rhythm in human music. Green arrows indicate our more encounter-based influences leading to tool industries. Both of our proposed scenarios agree on melody preceding advances in rhythm, but one treats acoustics as an indirect signal while the other treats it as a more direct implement of survival. Proposed anti-predation implements of our model are in orange. 
The fascinating possibilities that could emerge from our proposed evolutionary progression towards increasingly hominin-like behavior are unfortunately only quite thinly supported currently. The more extended speculations on aspects of terrestrialization, such as toward tool-use coemerging with drumming, as part of an acoustic defense system, cannot be entirely ruled out, but garner only rather modest support. Monotonic rhythm is very common not only in primates, but throughout vertebrates, and capacities for it (e.g. beat entrainment) may be hundreds of millions of years old (Honing, 2019). Furthermore, it should also be acknowledged that gibbons (and birds) do often exhibit exceptionally non-monotonic rhythmic complexity, hence somewhat complicating our proposed progression towards terrestrially associated advances in rhythmic capacities. Admittedly, a shift of final attention to rhythm stems from a sense of duty to address a musical loose-end in our more empirical work here on singing, which doesn't necessarily entail complex rhythmic patterns.

Nevertheless, we maintain the plausibility of such a scenario, however, as even the simplest (monotonic) rhythms still appear to occur more frequently in terrestrial rather than arboreal primate species (Table 6). Furthermore, it is worth emphasizing that artificially deep tones, as some other mammals produce (Garcia and Ravignani, 2020), are vastly more readily enabled via hominin bipedality by virtue of free-to-drum arms and hands. Being terrestrial also likely enabled hominins to use the ground as a sturdy and unyielding acoustic platform, permitting even more vigorous striking of inanimate, and perhaps resonant, objects—such as hollow logs. The initial use of nonsubstrate objects also reasonably involved throwing and hammering of tools perhaps as antipredation sound-making, particularly given that humans descended from apes who were very likely suspensory swingers. This is further supported by the tendency for terrestrialization to co-occur with tool use, more generally, among anthropoids (Meulman et al., 2012). As mentioned, such armswinging proclivities may have resulted in creation of initial stone blades which could have further inspired manufacture of other increasingly complex stone tool industries by later hominins.

To conclude, singing can be seen as a double-edged sword in matters of safety from predators. On the one hand, singing was likely a safety hazard—particularly in terrestrial environments, rich in predators. On the other hand, singing — particularly group singing and loud choruses—could have also benefited practitioners as a type of acoustic instrument for protection from predators, particularly upon terrestrial visitations, chiefly via an arboreal-descent form of the aforementioned Beau Geste effect. But more typical, competition-based, singing behavior appears to more commonly occur from positions of higher security—enabled by specialized escape via flight, avoidance via arboreality, and inconsumability via relatively larger size. We conclude that wider considerations of predation and trophic ranking in various environments might open new prospects in the further study of the evolution of proto-musical behavior in humans and other animal species. 
Binford, L. R. (1962) 'Archaeology as Anthropology’, American Antiquity, 28(2), pp. 217-225. doi: $10.2307 / 278380$.

Bispham, J. C. (2006) 'Rhythm in Music: What is it? Who has it? And Why?', Music Perception, 24(2), pp. 125-134.

Calvin, W. H. (1983) ‘A Stone’s Throw and its Launch Window: Timing Precision and its Implications for Language and Hominid Brains’, Journal of Theoretical Biology, 104, pp. 121-135.

Catchpole, C. K. (1987) 'Bird song, sexual selection and female choice’, Trends in Ecology \& Evolution, 2(4), pp. 94-97. doi: 10.1016/0169-5347(87)90165-0.

Catchpole, C. K. and Slater, P. J. B. (1995) Bird Song: Biological Themes and Variation. Cambridge, UK: Cambridge University Press.

Du, A. et al. (2018) 'Pattern and process in hominin brain size evolution are scale-dependent', Proceedings of the Royal Society B: Biological Sciences, 285(1873), p. 20172738. doi: 10.1098/rspb.2017.2738.

Ehrenreich, B. (2011) Blood rites: Origins and history of the passions of war. Granta Books.

Garcia, M. and Ravignani, A. (2020) 'Acoustic allometry and vocal learning in mammals', Biology Letters, 16(7), p. 20200081. doi: 10.1098/rsbl.2020.0081.

Geissmann, T. (1984) 'Pair-Bonding Function of Siamang (Hylobates-Syndactylus) Duet Song', International Journal of Primatology, 5, pp. 341-341.

Geissmann, T. (1993) Evolution of Communication in Gibbons. Zurich University.

Hagen, E. H. and Bryant, G. A. (2003) 'Music and dance as a coalition signaling system', Human Nature-an Interdisciplinary Biosocial Perspective, 14, pp. 21-51.

Harrington, F. H. (1989) 'Chorus howling by wolves: acoustic structure, pack size and the Beau Geste Effect.’, Bioacoustics, 2(2), pp. 117-136. doi: 10.1080/09524622.1989.9753122.

Hauser, M. D. and McDermott, J. (2003) 'The evolution of the music faculty: a comparative perspective’, Nature Neuroscience, 6, pp. 663-668.

Hobaiter, C. and Byrne, R. W. (2011) 'The gestural repertoire of the wild chimpanzee', Animal Cognition, 14(5), pp. 745-767. doi: 10.1007/s10071-011-0409-2.

Honing, H. (2019) The Evolving Animal Orchestra. Cambridge, MA: MIT Press.

Jordania, J. (2008) 'Origins of rhythm and the defence strategy of human ancestors', in Tsurtsumia, R. (ed.) Problems of Traditional Polyphony. Materials of the Third International Symposium on Traditional Polyphony. Third International Research Centre of Traditional Polyphony, Tbilisi State Conservatory, pp. 55-66.

Jordania, J. (2011) Why do people sing? The University of Melbourne: International Research Center for Traditional Polyphony.

Jordania, J. (2014) Tigers, Lions, and Humans: History of Rivalry, Coflict, Reverence, and Love. Logos. 
Jurmain, R. and Nelson, H. (1994) Introduction to Physical Anthropology. West Publishing Company.

Kortlandt, A. (1973) 'Primate Communication and the Gestural Origin of Language [and Comments and Reply]’, Current Anthropology, 14(1/2), pp. 5-24. doi: 10.1086/201401.

Krebs, J. R. (1977) 'The significance of song repertoires: The Beau Geste hypothesis', Animal Behaviour, 25, pp. 475-478. doi: 10.1016/0003-3472(77)90022-7.

Logue, D. M. and Hall, M. L. (2014) 'Migration and the evolution of duetting in songbirds', Proceedings of the Royal Society B: Biological Sciences, 281(1782), p. 20140103. doi: 10.1098/rspb.2014.0103.

Mehr, S. A. (2018) Natural History of Song Ethnography. Available at: http://osf.io/jmv3q.

Mehr, S. A. et al. (2020) 'Universality and diversity in human song', Science, 366(6468). doi: 10.1126/science.aax0868.

Meulman, E. J. M. et al. (2012) 'The Role of Terrestriality in Promoting Primate Technology', Evolutionary Anthropology: Issues, News, and Reviews, 21(2), pp. 58-68. doi: 10.1002/evan.21304.

Mikula, P. et al. (2020) 'A global analysis of song frequency in passerines provides no support for the acoustic adaptation hypothesis but suggests a role for sexual selection', Ecology Letters. Edited by G. Grether, p. ele.13662. doi: 10.1111/ele.13662.

Miller, G. F. (2000) 'Evolution of Human Music through Sexual Selection', in The Origins of Music. Cambridge, Massachusetts: MIT Press, pp. 328-360.

Murdock, G. P. and White, D. R. (1969) 'Standard Cross-Cultural Sample’, Ethnology, 8(4), p. 329. doi: 10.2307/3772907.

Murray, D. (2000) 'Haka Fracas? The Dialectics of Identity in Discussions of a Contemporary Maori Dance’, The Australian Journal of Anthropology, 11(2), pp. 345-357. doi: 10.1111/j.18359310.2000.tb00049.x.

Ravignani, A. et al. (2017) 'How small could a pup sound? The physical bases of signaling body size in harbor seals’, Current Zoology, 63(4), pp. 457-465. doi: 10.1093/cz/zox026.

Reichard, U. H., Hirai, H. and Bareli, C. (eds) (2016) Evolution of Gibbons and Siamang: Phylogeny, Morphology, and Cognition. Springer (Developments in Primatology: Progress and Prospects).

Schatral, A. (1990) 'Body Size, Song Frequency and Mating Success of Male Bush-Crickets Requena-Verticalis (Orthoptera, Tettigoniidae, Listrocelidinae) in the Field', Animal Behaviour, 40, pp. 982-984.

Schruth, D. M. (2005) Ballistics and the Evolution of Human Music. Masters Thesis Prospectus. University of Washington. Available at: http://dschruth.anthropoidea.org/theses/music-andballistics.html.

Schruth, D. M. (2006) Melodic Display as an Honest Signal of Remote Targeting Ability: A MetaAnalysis of the Correlated Evolution of Locomotion and Vocalizations in Primates. Masters Thesis. University of Washington. Available at: http://dschruth.anthropoidea.org/theses/melody-andtargeting.html. 
Schruth, D. M. and Templeton, C. N. (2014) 'Singing and swinging: The evolution of primate call structure as a function of substrate use', in American Society of Primatologists. 37th Annual Meeting, Atlanta, GA: American Journal of Primatology. doi: 10.1002/ajp.22382.

Schruth, D. M., Templeton, C. N. and Holman, D. J. (2019a) 'A definition of song, using human music universals observed in primate calls’, BioRxiv. doi: 10.1101/649459.

Schruth, D. M., Templeton, C. N. and Holman, D. J. (2019b) 'A definition of song, using human music universals observed in primate calls’, BioRxiv. doi: 10.1101/649459.

Slater, P. J. B. (2000) 'Birdsong Repertoires: Their Origins and Use’, in The Origins of Music. Cambridge, Massachusetts: MIT Press, pp. 49-63.

Susman, R. (1994) 'Fossil evidence for early hominid tool use', Science, 265(5178), pp. 1570_ 1573. doi: 10.1126/science.8079169.

Tappen, M. (1995) 'Savanna Ecology and Natural Bone Deposition: Implications for Early Hominid Site Formation, Hunting, and Scavenging’, Current Anthropology, 36(2), pp. 223-260. doi: $10.1086 / 204353$.

Wich, S. A. and Nunn, C. (2002) 'Do male "long distance calls” function in mate defense? A comparative study of long-distance calls in primates', Behavioral Ecology and Sociobiology, 52, pp. 474-484. 